\title{
Attending Code Status Discussions at Admission
}

\author{
Wendy G. Anderson, $M D, M S^{1,2}$, Rebecca Chase, $M D^{3}$, Steven Z. Pantilat, $M D^{1,2}$, \\ James A. Tulsky, $M D^{4,5}$, and Andrew D. Auerbach, MD, MPH
}

'Division of Hospital Medicine, University of California, San Francisco, CA, USA; ${ }^{2}$ Palliative Care Program, University of California, San Francisco, CA, USA; ${ }^{3}$ Department of Medicine, Stanford University, Stanford, CA, USA; ${ }^{4}$ Center for Health Services Research in Primary Care, Durham VA Medical Center, Durham, NC, USA; ${ }^{5}$ Center for Palliative Care, Department of Medicine, Duke University, Durham, NC, USA.

J Gen Intern Med 26(9):957

DOI: $10.1007 / \mathrm{s} 11606-011-1750-5$

(C) Society of General Internal Medicine 2011

Authors' reply—We thank Dr. Brauner and colleagues for their response to our article, and agree that discussions in which providers aim to convince patients to accept a DNR order are troublesome from both autonomy and physician-patient relationship perspectives. These discussions must instead be designed to ensure that code status be based on patients' goals and values. Thus, physicians must be willing to recommend that seriously ill patients receive CPR, if consistent with their goals and values. Further, though physicians should recommend attempting or withholding CPR based on patients' prognosis, goals and values, patients must retain the ability to refuse physicians' recommendations. Regarding the concern about singling out seriously ill patients for code status discussions, our intent is to target individuals who are most at risk for having the indication for a therapy-in this case CPR-so that their goals and values can inform whether they receive the therapy.

Aversion to planning one's own death is certainly a barrier to discussing and making decisions about life-sustaining therapies $^{1}$. We understand that in response, some advocate making DNR, rather than CPR, the default, given the procedure's low success rate, especially in seriously ill patients. However, we feel that changing the default status of CPR presents a serious challenge to patients' autonomy. In addition, selecting a subset of patients to be DNR presents significant logistical difficulties, given physicians' inability to predict outcomes of $\mathrm{CPR}^{2}$, and the not insignificant percentage of seriously ill patients who survive $\mathrm{CPR}^{3}$. Thus, as the alternative to CPR is certain death,

Published online June 3, 2011 and some patients find the achievable outcomes of CPR acceptable, we feel that patients should retain the right to decide about CPR, and that these decisions continue to be made in the context of physician-patient discussions.

We feel that discussing overall prognosis, with the patient's permission, is an important frame for CPR discussions with seriously ill patients, so long as patients can freely choose $\mathrm{CPR}^{4}$. Research indicates that physician-patient discussions about end-of-life issues and better understanding of prognosis are associated with decreased use of life-sustaining therapies, as well as better quality of life near the end of life for patients and their families ${ }^{5}$. However, the goal of discussing prognosis must not be to achieve a DNR order, but instead to ensure that treatments are best matched to patients' goals.

Corresponding Author: Wendy G. Anderson, MD, MS; Palliative Care Program, University of California, 521 Parnassus Avenue, Box 0903, San Francisco, CA 94143-0903, USA (e-mail: Wendy. Anderson@ucsf.edu).

\section{REFERENCES}

1. Kaufman S. And a time to die: how American hospitals shape the end of life. Chicago: University of Chicago Press; 2005.

2. Ebell MH, Bergus GR, Warbasse L, Bloomer R. The inability of physicians to predict the outcome of in-hospital resuscitation. J Gen Intern Med. 1996;11(1):16-22.

3. Reisfield GM, Wallace SK, Munsell MF, Webb FJ, Alvarez ER, Wilson GR. Survival in cancer patients undergoing in-hospital cardiopulmonary resuscitation: a meta-analysis. Resuscitation. 2006;71(2):152-60.

4. Thaler RH, Sunstein CR. Nudge: improving decisions about health, wealth, and happiness. New York: Penguin Books; 2009.

5. Wright AA, Zhang B, Ray A, et al. Associations between end-of-life discussions, patient mental health, medical care near death, and caregiver bereavement adjustment. JAMA. 2008;300(14):1665-73. 